\title{
Short-time test for evaluating the machinability of alloys
}

\author{
M. Alvarado ${ }^{1}$, H. Siller ${ }^{2}$, P. Zambrano ${ }^{1}$, C. Rodríguez ${ }^{2}$, \\ M. A. Rodríguez ${ }^{1}$, A. Juárez ${ }^{1}$, H. Toscano ${ }^{2}$ \& A. Mascareñas ${ }^{3}$ \\ ${ }^{I}$ Facultad de Ingeniería Mecánica y Eléctrica, \\ Universidad Autónoma de Nuevo León, NL, México \\ ${ }^{2}$ Instituto Tecnológico de Estudios Superiores de Monterrey, \\ Campus Monterrey, NL, México \\ ${ }^{3}$ American Standard, NL, Mexico
}

\begin{abstract}
Machinability is an important property of materials, especially because it affects the manufacturing cost of products. Since there is no accepted definition of machinability, there is no accepted test for measuring it. Researchers have studied two dimensional cutting forces, chip thickness, using orthogonal cutting models, others have concentrated on comparing three dimensional cutting forces, surface roughness and power consumption in oblique cutting. All these tests converge in the necessity of determining which material has better machinability. In this paper machinability tests by other authors are reproduced, proper modifications are made, to visualize which test should be considered and which to discard in the measurement of machinability.
\end{abstract}

Keywords: cutting force, thrust force, surface roughness, cutting temperature, orthogonal cutting, emissivity, chip morphology, dynamometer.

\section{Introduction}

Machinability is a measure of ease with which a work material can satisfactorily be machined. The machinability aspect is of considerable importance for production engineers so that processing can be planned in an efficient manner [1]. The expenses for removing material from a workpiece during a manufacturing process reach more than US\$100 billion yearly in the United States and only four machining processes are responsible for $75 \%$ of this value 
which are turning, drilling, milling and grinding [2]. Since there is no universally accepted methodology for evaluating machinability and numerous new materials enter the market every year, many manufacturers are encountering difficulties in selecting the most appropriate material for their products [1].

Machinability takes into account many variables, such as tool life, cutting forces, specific power consumption, surface finish, temperature generated, noise and chip characteristics. Tool life has been the classical machinability test for many years. This article presents a different approach.

\section{Literature review}

Some investigators developed orthogonal tests for measuring machinability, chip thickness, shear planes, two dimensional cutting forces, Merchant circle, tool life and tool wear analysis are made using cylindrical samples. Özel and Kapart [3] propose finite element methods to predict cutting forces, stresses and cutting temperature based on orthogonal cutting data and a work material constitutive model. The results are close to the experimental data in different cases which shows a powerful tool for two-dimensional machining predictions. Unfortunately just a few industrial processes are orthogonal major machining process are oblique.

Thiele et al. [4] presented ASTM E618 test accelerated with harder tools, to compare machinability of brass, aluminium and steel. Dabade and Joshi [5] measured undeformed chip thickness and chip thickness and uses shear plane relation to establish the differences in $\mathrm{Al} / \mathrm{Si}$ composites with different particle size. Vilarinho et al. [6] perform three dimensional force measurement under one cutting condition, 27 different brass alloys are tested relations between hardness, roughness, cutting forces and chemical compositions are shown.

Dasch et al. [7] realized drilling test on aluminium with lead, bismuth, tin, and indium as alloying elements, in this research spindle power is measured, also cutting temperature is recorded by a thermographic camera. Pereira et al. [2] show a tool wear analysis for evaluate the effect of sulphur in gray cast iron, tool life criteria is $0.3 \mathrm{~mm}$ of flank wear, this work compares the tool wear vs. cutting time, for three gray cast iron alloys with different sulphur content, cylindrical samples were used.

Fang and $\mathrm{Wu}[8]$ compared two dimensional cutting forces in high speed machining of T6Al4V and Inconel 718 experiment consist in five cutting speeds and four feed rates. The results compare these two alloys under same cutting conditions and set-up, a total of twelve empirical regressions relations between cutting forces, feed forces and force ratio are presented. Arrazola et al. [9] analyzed Ti555.3 and Ti6Al4V under tool wear criteria for machinability, tool wear vs. cutting velocity is shown, the feed rate and depth of cut is constant varying cutting speed from $40 \mathrm{~m} / \mathrm{min}$ to $90 \mathrm{~m} / \mathrm{min}$. Tool life criteria is based on $0.3 \mathrm{~mm}$ of flank wear. Chip morphology is visualized under microscope finding adiabatic shear bands in the chips. Ebrahimi and Moshksar [10] compares the machinability of microalloyed steels (30MnVS6) and quenched-tempered (QT) steels (AISI 1045 and AISI 5140). A turning test was made over cylindrical 
specimens two-dimensional cutting forces are measured; chip analysis and chip/contact length is calculated.

Lopez [13] performed a temperature analysis in aluminium 6063 alloy during milling, an infrared thermometer is used, and data is recorded and exponential fit is obtained from the lectures.

\section{Experimental procedure}

The experimental plan and setup is presented for each test; the purpose is to try the most of the tests included in the literature by others researchers, to demonstrate which are more significant for machinability measurement. We intended to compare the experiments developed by others researches instead of comparing their results. All the samples were melted in a medium frequency induction furnace, a tilt casting process using copper-nickel permanent mold with graphite coating was used for obtaining the solid bar samples, $150 \mathrm{~mm}$ long and $30 \mathrm{~mm}$ diameter, samples consist in the same base alloy CuZn38 just varying $1 \%$ of composition with alloying elements, samples are denominated A1, B2, C3, D4. Samples chemical composition is been review for patent possibility, so no composition is presented. For the objective of this study no composition is needed just know that samples are distinguishable.

\subsection{Roughness test}

The experimental plan for surface roughness was laboured in a HAAS SL-10 CNC Lathe, since feed is the most relevant factor a first experiment for 8 levels of feeds are developed at two cutting speeds over a $60 \mathrm{~mm}$ cutting length, with 3 replicas for each cutting condition is realized. In this experiment feed speed $(\mathrm{mm} / \mathrm{seg})$ as primary variable instead of feed rate $(\mathrm{mm} / \mathrm{rev})$ because feed speed

Table 1: $\quad$ Roughness experimental plan.

\begin{tabular}{|l|l|l|l|l|}
\hline \multicolumn{3}{|c|}{ Experiment \#1 } & \multicolumn{2}{c|}{ Experiment \#2 } \\
\hline $\begin{array}{l}\text { Feed velocity } \\
(\mathrm{mm} / \mathrm{seg})\end{array}$ & $\begin{array}{c}\text { Cutting } \\
\text { velocity 1 } \\
(\mathrm{m} / \mathrm{min})\end{array}$ & $\begin{array}{c}\text { Cutting } \\
\text { velocity } 2 \\
(\mathrm{~m} / \mathrm{min})\end{array}$ & $\begin{array}{c}\text { Feed rate } \\
(\mathrm{mm} / \mathrm{rev})\end{array}$ & $\begin{array}{c}\text { Cutting } \\
\text { velocity } \\
(\mathrm{m} / \mathrm{min})\end{array}$ \\
\hline 2 & 59 & 94.5 & 0.1172 & 94.5 \\
\hline 2.5 & 59 & 94.5 & 0.1406 & 94.5 \\
\hline 3 & 59 & 94.5 & 0.1641 & 94.5 \\
\hline 3.5 & 59 & 94.5 & 0.1875 & 94.5 \\
\hline 4 & 59 & 94.5 & 0.2109 & 94.5 \\
\hline 4.5 & 59 & 94.5 & 0.2625 & 59 \\
\hline 5 & 59 & 94.5 & 0.2667 & 66 \\
\hline 5.5 & 59 & 94.5 & 0.27 & 73.8 \\
\hline & & & 0.3 & 59 \\
\hline & & & 0.3375 & 59 \\
\hline
\end{tabular}


compare the surface roughness with the machining time, for industrial processes this parameter affects the production rate and is never included in machining tests. The second experiment compares the feed rate with the $\mathrm{R}_{\mathrm{a}}$. In this experiment lubricant is used because thermal energy released from the cut modifies the surface characteristics. The tool used for this experiment was a cemented carbide insert DNMG $150408 \mathrm{NN}$ grade LT-10. The arithmetic value of roughness $R_{a}$ is measured with a Mitutoyo profilometer, model 178-293-2A, series 500153 , the measure temperature is $19^{\circ} \mathrm{C}-21^{\circ} \mathrm{C}$, the relative humidity $40 \%-60 \%$, the standard used is JIS' 94 , the cut-off is $0.8 \mathrm{~mm} \times 5$, the evaluation length is $4 \mathrm{~mm}$.

\subsection{Chip morphology test}

During the roughness test chips from different conditions were collected. The chips collected are dried, cold mounted in acrylic resin, polished and chemical attacked to reveal microstructure using an optical microscope qualitative characteristics are observed. For slow feeds semi-long curl chips are formed, and for high feeds segmented toothed chips were formed. Because it is not an orthogonal cut we are not interested in measure chip thickness and made relations. Optical micrographs are taken, and important characteristics are measured using an image analyzer.

\subsection{Power consumption test}

Power turning test was improved in a conventional lathe by measuring the current increment in one phase of the lathe motor at one fixed cutting condition. The current was read exactly before the cut starts and during the middle of the cut. The lathe used was an Emco Maximat V13, with a 220 VAC motor, $60 \mathrm{~Hz}$, 9 amps and 0.83 of power factor. The fixed parameters of cut were 1180 RPM, $0.225 \mathrm{~mm} / \mathrm{rev}$, depth of cut $2.7 \mathrm{~mm}$ and the length of cut was $66.3 \mathrm{~mm}$, no lubricant was used, balanced phases of the motor are assumed.

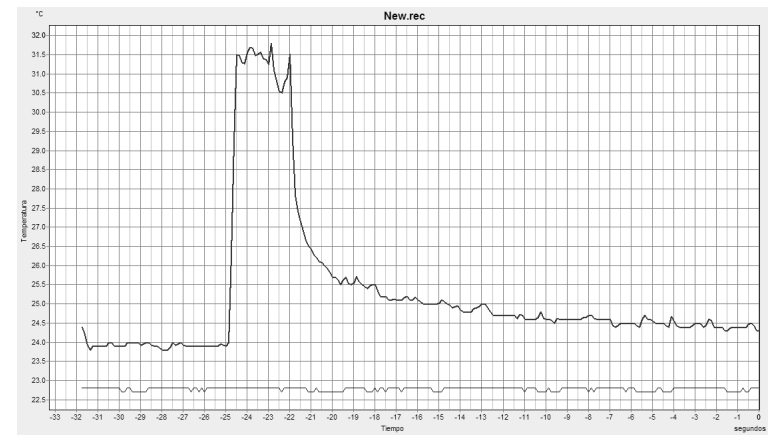

Figure 1: Temperature measured for $80 \mathrm{~m} / \mathrm{min}, 0.3 \mathrm{~mm} / \mathrm{rev}, 2$ sec cutting time on D4 sample. 


\subsection{Surface temperature test}

The surface temperature is measured by an infrared non-contact thermometer Fluke 574, with RS232 data recording capability, the emissivity of the surface was calibrated by measuring the sample surface temperature and with type $\mathrm{K}$ thermocouple, taking readings until they match. This test is realized together with the cutting forces measurement on D4 sample so that temperature generated and cutting forces could be related. The temperature is measured $0.125 \mathrm{~ms}$ the resultant data is then exported to a file for analysis.

\subsection{Three dimensional cutting forces test}

In the cutting forces experiment solid bars are machined in a $\mathrm{CNC}$ lathe Milltronics ML14 with $9 \mathrm{~kW}$ spindle power and a maximum of $4500 \mathrm{rpm}$, the tool insert used is a cemented carbide insert DNMG 150408, $0.8 \mathrm{~mm}$ corner radius, $4.76 \mathrm{~mm}$ thickness $0^{\circ}$ clearance angle and $15 \mathrm{~mm}$ of cutting length. The experimental design for the test is a two factors and three level central composite design with one center point and an alpha value of one.

A total of 9 runs, three cutting velocities and three feed rates, and three replicas are done. The cutting force $F_{z}$, the feed force $F_{x}$ and the radial force $F_{y}$ are measured by using a three component dynamometer Kistler 9257B, a Kistler 5814B1 multichannel charge amplifier and a Tektronix oscilloscope. First we place the zero on the oscilloscope interface then the forces are recorded in the oscilloscope, and data is exported to file. With the oscilloscope cursors we measure the increments in voltage and convert with the amplifier gain into mechanical units. We confirm the measure by plotting the voltage vs. time obtained in the exported files.

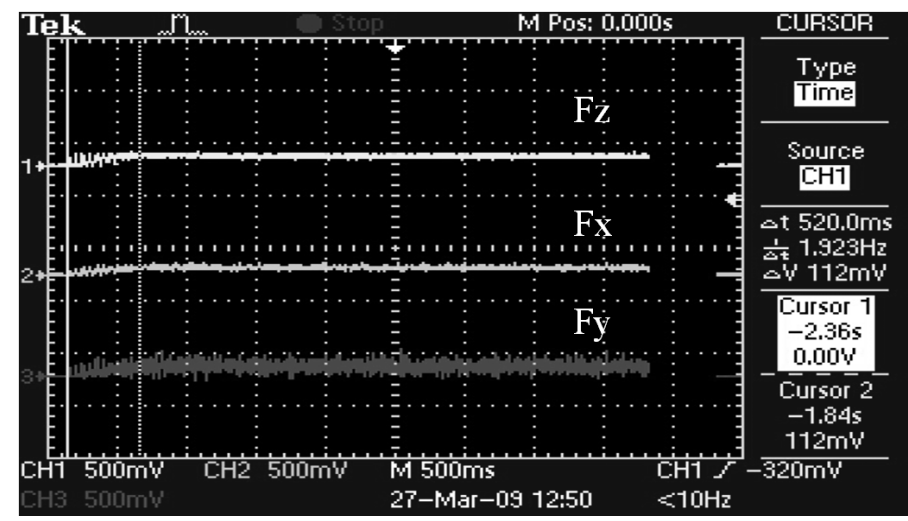

Figure 2: Oscilloscope interface with the three component forces from the dynamometer. 


\section{Experimental results}

\subsection{Roughness results}

The common values reported in the measure or roughness is $R_{a}$ arithmetic mean value defined by eqn (1), but there are other measures of roughness that are critical depending on the application, so we complement the measurement by calculating $\mathrm{R}_{\mathrm{z}}$ ten point height eqn (2) and $\mathrm{R}_{\mathrm{y}}$ maximum peak-to-valley.

$$
\begin{gathered}
R a=\frac{1}{n} \cdot \sum_{i=1}^{n}\left|f\left(x_{i}\right)\right| \\
R z=\frac{\left(R_{1}+R_{3}+R_{5}+R_{7}+R_{9}\right)+\left(R_{2}+R_{4}+R_{6}+R_{8}+R_{10}\right)}{5}
\end{gathered}
$$

For the first experiment fig. 3 shows the difference in arithmetic roughness changing the cutting velocity, but it is because of the inherent decrease in feed rate. So even though the cutting velocity has an impact in roughness considering feed velocity in the " $x$ " axis, feed rate is still the most predominant factor in the $R_{a}, R_{y}$ and $R_{z}$ measure. No significantly differences were found between $R_{a}, R_{z}$ and $\mathrm{R}_{\mathrm{y}}$ of $\mathrm{B} 2$ and $\mathrm{C} 3$ samples in the first experiment. However, the second experiment shown in fig. 4 results in differences between $\mathrm{A} 1, \mathrm{~B} 2$ and $\mathrm{C} 3$ samples. A polynomial quadratic fit is obtained for each sample. Eqns (3), (4) and (5) show the $\mathrm{R}_{\mathrm{a}}$ as a function of the feed " $\mathrm{f}$ ". The $\mathrm{R}^{2}$ values for the equations are 0.9269 for $\mathrm{A} 1,0.9723$ for $\mathrm{B} 2$, and 0.9963 for $\mathrm{C} 3$.

$$
\begin{aligned}
& A 1 R_{a}(f)=-35.508 f^{2}+23.205 f-1.0463 \\
& B 2 R_{a}(f)=32.495 f^{2}-0.4726 f+0.8789 \\
& C 3 R_{a}(f)=38288 f^{2}-1.3513 f+0.6059
\end{aligned}
$$

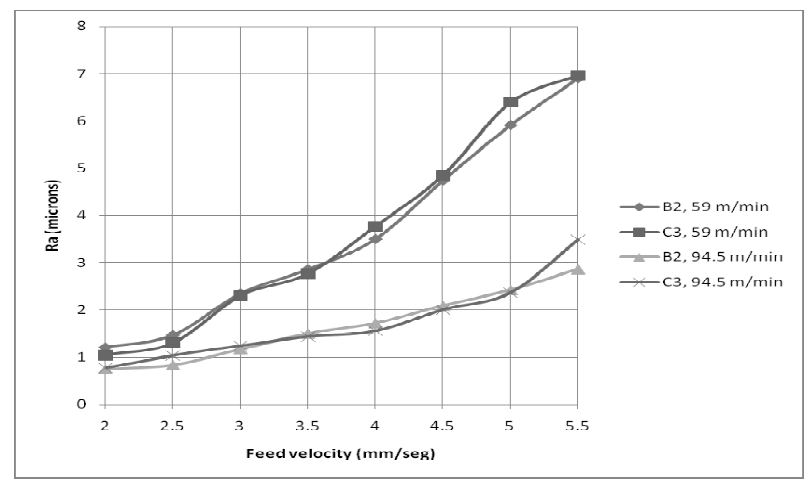

Figure 3: First experiment; B2 and C3 samples are compared under same conditions. No differences are obtained graphing feed velocity. 


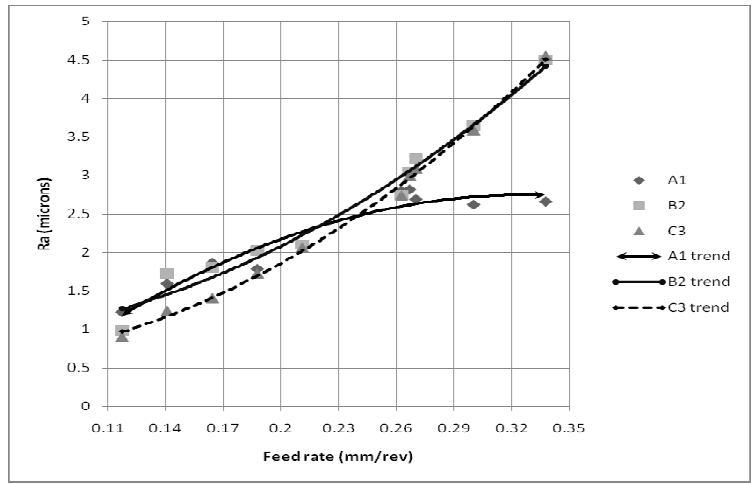

Figure 4: $\quad$ Second experiment; Differences between the $\mathrm{R}_{\mathrm{a}}$ of the samples is clearly shown, a quadratic fit is obtained from this test.

\subsection{Power consumption results}

The specific power is the power required to remove a unit volume per unit time. The specific and total power is related by eqn. (6), according to [12] the specific power consumption can also be calculated by eqn. (7), where it is related to the cutting force, the cutting velocity and the material removal rate,.

$$
\Delta P=P_{s} \cdot M R R
$$

So we proceed to measure the current increments in the conventional lathe motor. They were 6 replicas for each experiment; the standard deviation is taken as the variation. The MMR or material removal rate was $31,472 \mathrm{~mm}^{3} / \mathrm{min}$. The values in table 2 are not far from what [12] has shown of others experiments.

Table 2: $\quad$ Results of the power consumption test.

\begin{tabular}{|c|c|c|c|c|}
\hline Sample & $\begin{array}{c}\text { Current } \\
\text { increment } \\
\text { (amps) }\end{array}$ & $\begin{array}{c}\text { Power } \\
\text { increments } \\
\text { (watts) }\end{array}$ & $\begin{array}{c}\text { Specific } \\
\text { cutting power } \\
\left(\mathrm{kW} / \mathrm{mm}^{3} / \mathrm{min}\right)\end{array}$ & Variation \\
\hline A1 & 0.875 & 333.38 & $1.06 \times 10^{-5}$ & $9 \%$ \\
\hline B2 & 0.7891 & 300.65 & $0.955 \times 10^{-5}$ & $20.8 \%$ \\
\hline C3 & 0.7783 & 296.54 & $0.942 \times 10^{-5}$ & $7 \%$ \\
\hline D4 & 0.9033 & 344.16 & $1.09 \times 10^{-5}$ & $11.3 \%$ \\
\hline
\end{tabular}

\subsection{Chip morphology}

The chips in this analysis were collected from the roughness experiment. The chip morphology qualitative analysis reveals certain characteristics occurring in chips. In fig. 5 chip sample of B2 at $0.1172 \mathrm{~mm} / \mathrm{rev}, 94.5 \mathrm{~m} / \mathrm{min}$ and $2 \mathrm{~mm}$ and sample of B2 at $0.3 \mathrm{~mm} / \mathrm{rev}, 59 \mathrm{~m} / \mathrm{min}$ and $2 \mathrm{~mm}$ of depth of cut. Notice the difference in the same alloy under different cutting conditions, this shows us that different phenomenon is happening during cutting. 
162 Computational Methods and Experiments in Materials Characterisation IV

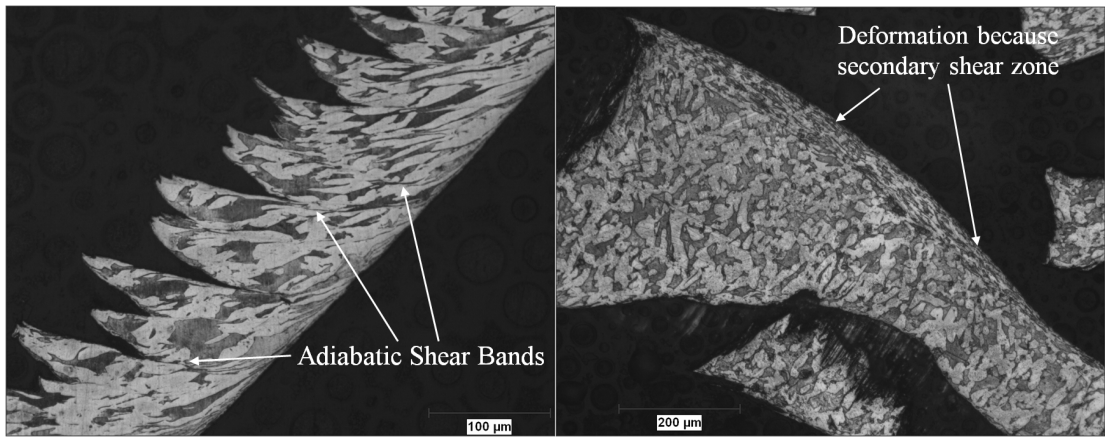

Figure 5: The chip showing different characteristics according to its cutting conditions.

Table 3: $\quad$ Results of the surface temperature experiment.

\begin{tabular}{|l|l|l|l|l|}
\hline $\begin{array}{l}\text { Cutting } \\
\text { velocity } \\
(\mathrm{m} / \mathrm{min})\end{array}$ & $\begin{array}{l}\text { Feed rate } \\
(\mathrm{mm} / \mathrm{rev})\end{array}$ & $\begin{array}{l}\text { Cutting force } \\
(\mathrm{N})\end{array}$ & $\begin{array}{l}\text { Ambient } \\
\text { temperature } \\
\left({ }^{\circ} \mathrm{C}\right)\end{array}$ & $\begin{array}{l}\text { Surface } \\
\text { Temperature } \\
\left({ }^{\circ} \mathrm{C}\right)\end{array}$ \\
\hline 40 & 0.1 & 80 & 24 & 30 \\
\hline 40 & 0.2 & 144 & 23.5 & 28.5 \\
\hline 40 & 0.3 & 180 & 22.5 & 26.5 \\
\hline 60 & 0.1 & 72 & 24 & 35 \\
\hline 60 & 0.2 & 160 & 23.5 & 28.5 \\
\hline 60 & 0.3 & 224 & 23.4 & 30.9 \\
\hline 80 & 0.1 & 64 & 23 & 33 \\
\hline 80 & 0.2 & 112 & 24 & 32.5 \\
\hline 80 & 0.3 & 216 & 24 & 31.6 \\
\hline
\end{tabular}

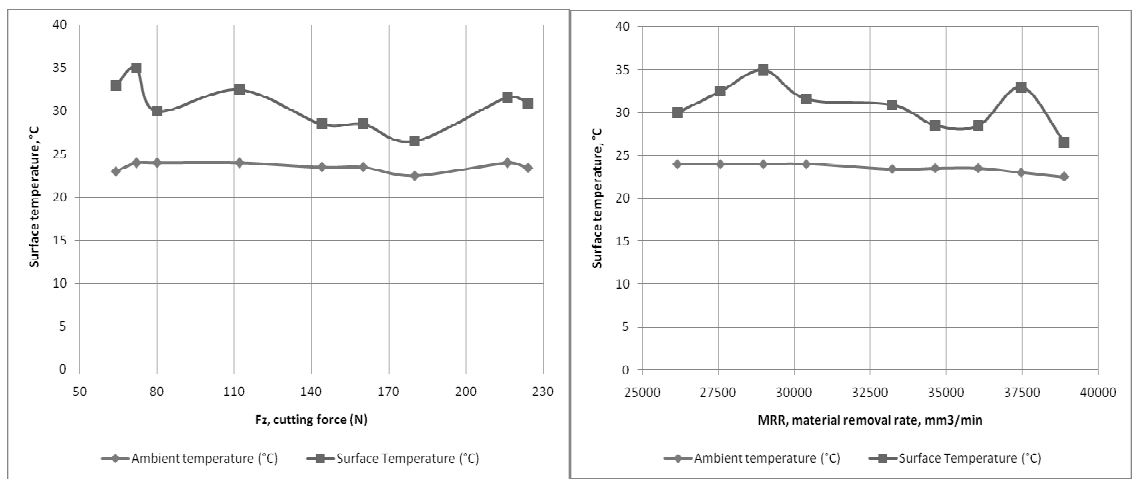

Figure 6: The results show no relation between the cutting forces and surface measure, and no relation between MRR and surface temperature. 


\subsection{Surface temperature}

The emissivity of $\mathrm{C} 3$ sample is 0.6 under this parameter the corresponding temperatures are measured. Because the infrared spectrum cover a wide range of wavelengths ( 0.78 to 500 microns) of the thermal radiation is useful in the measurement of surface temperature. The results show no relation in surface temperature and cutting velocity, surface temperature and cutting force, and surface temperature and material removal rate. It has to be clear that surface temperature differs from average tool/chip contact temperature.

\subsection{Cutting forces}

The voltage increment measured were transformed to mechanical units, the conversion were $1000 \mathrm{MU} /$ volt so a direct conversion to newtons $112 \mathrm{mV}$ represents $112 \mathrm{~N}$. The data obtained in this test is subject to multiple regression analysis, and to pareto regression coefficients to determine which variable has a major influence on each cutting force. The multiple regression analysis shows eqns. (7), (8), (9) and a value of $\mathrm{R}^{2}$ of $0.7212,0.6170$ and 0.9447 respectively.

$$
\begin{gathered}
F_{x}=110.74-0.777 V_{c}+30.778 f+6.5 V_{c} f \\
F_{y}=221.04-1.778 V_{c}+76.667 f+29.33 V_{c} f \\
F_{z}=136.41-6.611 V_{c}+65.33 f+9 V_{c} f
\end{gathered}
$$

Table 4: $\quad$ Results of the cutting forces experiment.

\begin{tabular}{|l|l|l|l|l|l|l|}
\hline $\begin{array}{c}\text { Cutting } \\
\text { velocity } \\
(\mathrm{m} / \mathrm{min})\end{array}$ & $\begin{array}{l}\text { Feed rate } \\
(\mathrm{mm} / \mathrm{rev})\end{array}$ & \multicolumn{1}{|c|}{ Fx } & \multicolumn{1}{|c|}{ Fy } & \multicolumn{1}{|c|}{ Fz } & $\begin{array}{c}\text { Resultant } \\
\text { force }\end{array}$ & Fz/Fx \\
\hline 40 & 0.1 & 88 & 169.33 & 77.33 & 205.90 & 0.878 \\
\hline 40 & 0.2 & 106.66 & 253.33 & 155.66 & 315.88 & 1.459 \\
\hline 40 & 0.3 & 141.33 & 246.66 & 188 & 340.82 & 1.330 \\
\hline 60 & 0.1 & 78.66 & 113.33 & 68 & 153.80 & 0.864 \\
\hline 60 & 0.2 & 120 & 246.66 & 154.66 & 314.89 & 1.288 \\
\hline 60 & 0.3 & 130.66 & 301.33 & 202.66 & 385 & 1.551 \\
\hline 80 & 0.1 & 71.33 & 120 & 58.66 & 151.42 & 0.822 \\
\hline 80 & 0.2 & 109.33 & 314.66 & 117.33 & 353.17 & 1.073 \\
\hline 80 & 0.3 & 150.66 & 314.66 & 205.33 & 404.80 & 1.362 \\
\hline
\end{tabular}

\section{Conclusions}

We draw the following conclusions:

- In the roughness test most important factor is feed rate, instead of feed velocity, but machining time is important because it affects the production rates. Differences are appreciable in fig. 4.

- Also for this same experiment we could obtain a quadratic polynomial fit which is necessary for predict roughness. Roughness test should be considered in any machining test. 


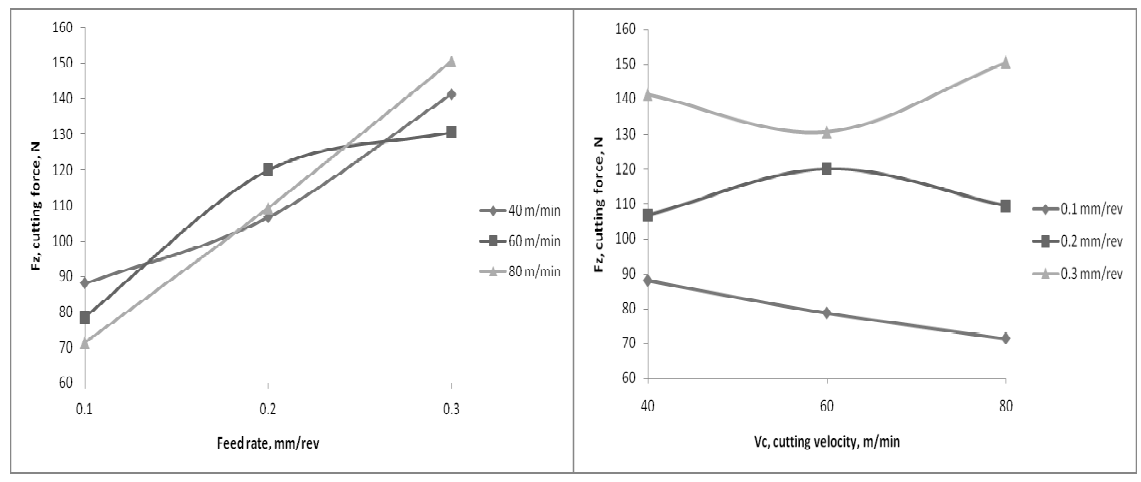

Figure 7: Relations between feed rate and cutting force, and relation between cutting velocity and cutting force.

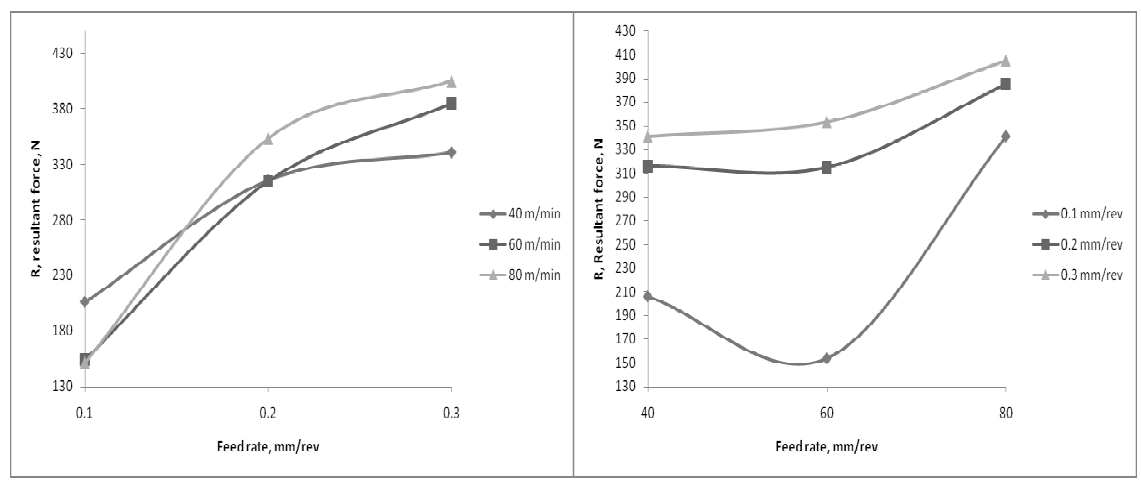

Figure 8: Relationship between the feed rate and the resultant force, and relationship between cutting velocity and resultant force.

- Power consumption test is easy and fast, although results are good in accordance to data presented in [12], the variation presented in samples B2 and D4 demonstrate the necessity of explore more cutting conditions and/or more replicas.

- Chip morphology is a successful and important test that should be considered in every machining test. Although experience is necessary to interpret the corresponding micrographs, but it can show to us the characteristic phenomenon occurring at different conditions.

- Surface temperature has no relation with cutting velocity, or cutting force, or material removal rate, so a surface temperature test by a radiation method with an infrared thermometer may not be as relevant as one could expect. Thermographic methods could be more efficient as Dasch [7] presented.

- Cutting forces test, in three dimensions is a very liable test, capable of analyze and predict different conditions; effectiveness of these methods relies in the experimental design and the number of replicas. 
The proposal is an integrated experiment, which includes the measure of $R_{a}$, $R_{y}$ and $R_{z}$, three-dimensional cutting forces, and chip morphology analysis. The validity of the data relies in the robustness of the experimental design and not in the collecting method. It is necessary to record machining time and material removal rate for each cutting condition. The surface temperature and power consumption is optional; orthogonal cutting experiment could be helpful in the obtaining of cutting models and comparison with oblique cutting is interesting.

\section{References}

[1] Rao, R. Ventaka, "Machinability evaluation of work materials using a combined multiple attribute decision-making method", Int. J Adv Manuf Technol doi:10.1007/s00171-004-2348-4.

[2] Pereira A.A., Boehs L., Guesser W., "The influence of sulfur on the machinability of gray cast iron FC25" J Mater. Process. Tech doi:10.1016/j.matprotec.2006.03.100.

[3] Özel T., Kapart Y., "Predictive Analytical and Thermal Modeling of Orthogonal Cutting Process - Part I: Predictions of Tool Forces, Stresses, and Temperature Distributions". Journal of Manufacturing Science and Engineering. ASME. doi:10.1115/1.2162590

[4] Thiele E., et al., "Comparative machinability of brasses, steels and aluminum alloys", Copper Development Association, Inc.

[5] Dabade, U.A., Joshi, S.S., "Analysis of chip formation mechanism in machining $\mathrm{Al} / \mathrm{SiCp}$ metal matrix composites". J Mater. Process. Tech (2009), doi:10.1016/j.matprotec.2008.10.057

[6] Vilarinho, C., Davim, J.P., Soares D., Castro, F., Barbosa J., "Influence of the chemical composition in the machinability of brasses". J Mater. Process. Tech (2005), doi:10.1016/j.matprotec.2005.05.035

[7] Dasch, J.M., et al., "The effect of free-machining elements on dry machining of B319 aluminum alloy”. J. Mater. Process. Tech. (2009), doi:10.1016/j.jmatprotec.2008.11.041v

[8] Fang, N., Wu, Q., "A comparative study of the cutting forces in high speed machining of Ti-6Al-4V and Inconel 718 with a round cutting edge tool". J. Mater. Process. Tech. (2008) doi:10.1016/ j.jmatprotec.2008.10.013

[9] Arrazola, P.-J., et al., "Machinability of titanium alloys (Ti6Al4V and Ti555.3)". J. Mater. Process. Tech. (2008), doi:10.1016/ j.jmatprotec.2008.03.020

[10] Ebrahimi, A., Moshksar, M.M., "Evaluation of machinability in turning of microalloyed and quenched-tempered steels: Tool wear, statistical analysis, chip morphology". J. Mater. Process. Tech. (2008), doi:10.1016/j.jmatprotec.2008.02.067

[11] Childs, T. Maekawa K., Obikawa T., Yamane Y., Metal Machining Theory and Applications. John Wiley \& Sons Inc. New York - Toronto, pp. 144-166, 2000.

[12] ASM Metals handbook. Volume 16 "Machining" 1989. 
166 Computational Methods and Experiments in Materials Characterisation IV

[13] Lopez E., "Estudio de maquinabilidad para aleaciones de aluminio AlMgSi 6063", Doctoral thesis, 2002, Facultad de Ingeniería Mecánica y Eléctrica, UANL. 